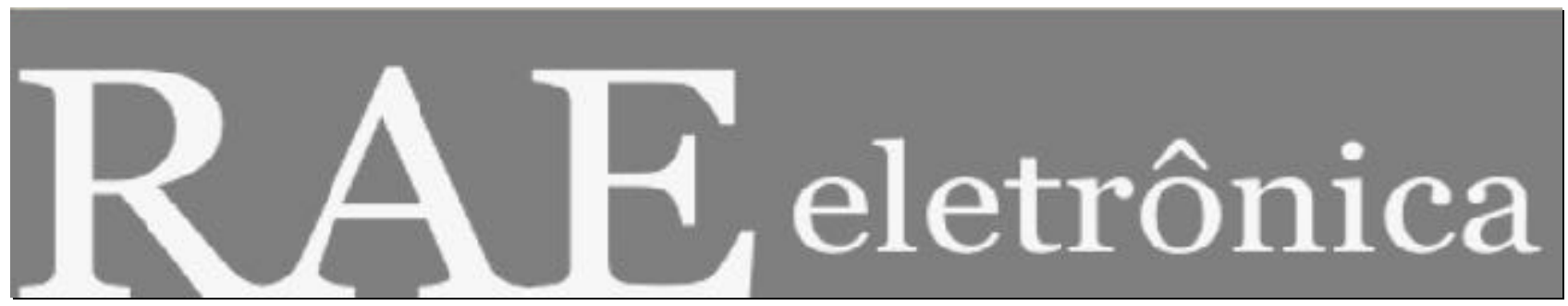

\title{
RESPONSABILIDADE SOCIAL CORPORATIVA: LIMITES E POSSIBILIDADES
}

\author{
Por:

\section{Jocimari Tres Schroeder \\ Ivanir Schroeder}

RAE-eletrônica, v. 3, n. 1, Art. 1, jan./jun. 2004

http://www.rae.com.br/eletronica/index.cfm?FuseAction=Artigo $\& I D=1573 \&$ Secao=COMPTO\&Volu $\mathrm{me}=3 \& \mathrm{~N}$ umero $=1 \& \mathrm{Ano}=2004$

CCopyright, 2004, RAE-eletrônica. Todos os direitos, inclusive de tradução, são reservados. É permitido citar parte de artigos sem autorização prévia desde que seja identificada a fonte. A reprodução total de artigos é proibida. Os artigos só devem ser usados para uso pessoal e nãocomercial. Em caso de dúvidas, consulte a redação: redacao@ rae.com.br.

A RAE-eletrônica é a revista on-line da FGV-EAESP, totalmente aberta e criada com o objetivo de agilizar a veiculação de trabalhos inéditos. Lançada em janeiro de 2002, com perfil acadêmico, é dedicada a professores, pesquisadores e estudantes. Para mais informações consulte o site www.rae.com.br/eletronica.

\section{RAE-eletrônica}

ISSN 1676-5648

(C)2004 Editora: Fundação Getulio Vargas - Escola de Administração de Empresas de São Paulo.

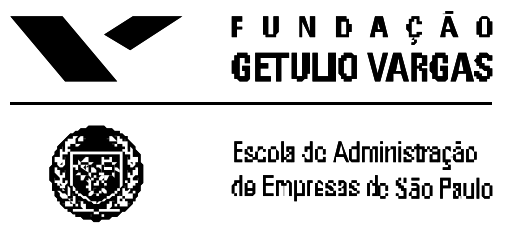




\title{
RESPONSABILIDADE SOCIAL CORPORATIVA: LIMITES E POSSIBILIDADES
}

\section{RESUMO}

Neste artigo busca-se refletir sobre a influência da responsabilidade social nas ações das empresas. A teoria da delimitação dos sistemas sociais de Ramos (1989), é base para tal reflexão. A responsabilidade social corporativa é justificada e defendida, tanto pelas empresas, sociedade e Estado, como um fenômeno que delimita as ações empresariais. No entanto, argumenta-se que ao invés de delimitar as ações, a responsabilidade social pode acabar por ampliar o poder das empresas.

\begin{abstract}
The aim of this article is to reflect on the influence of social responsibility in companies' activities. The reflection is based on Ramos' (1989) theory of social system delimitation. Corporate social responsibility is justified and defended not only by companies, society and state, as a phenomenon that delimits companies' activities. However, it is also argued that social responsibility may actually end up enhancing their power rather than delimiting their activities.
\end{abstract}

\section{PALAVRAS-CHAVE}

Delimitação dos sistemas sociais, responsabilidade social corporativa, paradigma econômico, paradigma paraeconômico.

\section{KEY-WORDS}

Social system delimitation, corporate social responsibility, economic paradigm, paraeconomic paradigm. 


\section{INTRODUÇÃO}

O cotidiano da humanidade mais do que nunca está constituído por organizações, que representam um esforço coletivo para se atingir determinados fins. As organizações são parte integrante da sociedade. Pode-se citar, dentre tantas: os hospitais, teatros, escolas, igrejas, universidades, prefeituras, clubes, empresas.

Para Wood Jr. (2001, p. 181), "nós humanos cultivamos com estranha persistência o hábito de nos tornarmos vítimas das armadilhas que nós mesmos criamos. Nestes termos, organizações parecem ser uma de nossas obras máximas". A empresa, caracterizada como uma organização com fins lucrativos, foi especialmente durante o século XX, o mais importante meio de acumulação de riquezas.

Destaca-se assim, a importância das empresas, sustentáculos do paradigma de mercado, da acumulação de riquezas, sendo o critério fundamental de ordenamento da sociedade. Neste contexto, emerge a responsabilidade social corporativa - o envolvimento das empresas em causas sociais.

Este artigo pretende analisar a responsabilidade social corporativa de forma a não somente legitimá-la, mas, principalmente, na busca de uma maior reflexão sobre as suas raízes e influência social. Além disso, argumenta-se sobre uma conseqüência entendida como inevitável, a ampliação do poder das empresas ao assumirem causas sociais.

Devido a esta ampliação de poder, surge a necessidade de delimitar a atuação da empresas em tais causas. Considera-se que a Teoria da Delimitação dos Sistemas Sociais, de Alberto Guerreiro Ramos, contenha fundamentos teóricos importantes, que além de fundamentar a necessidade da delimitação da responsabilidade social corporativa, apresenta uma alternativa para a reconceitualização dos sistemas sociais.

A Teoria da Delimitação dos Sistemas Sociais sugere a adoção de outro paradigma social, denominado de paraeconômico. Assim, este artigo discute a importância da Teoria da Delimitação dos Sistemas Sociais, que por meio do paradigma paraeconômico, propõe a delimitação da atuação dos diversos atores sociais, evitando a sobreposição do poder de um ator em especial.

\section{AS RAÍZES HISTÓRICAS DA RESPONSABILIDADE SOCIAL CORPORATIVA}

Buscar as raízes ou o sentido completo e acabado de um fenômeno social, além de ser temerário, é no mínimo pretensioso. O fenômeno social envolve e é provocado pelo seu agente, o homem. Flyvbjerg (1994, p. 342), argumenta que "o homem é auto-interpretativo e, não pode de maneira exata ser previsível, porque depende do contexto, dificultando a simples redução a um conjunto de regras".

Porém, torna-se um desafio entender o homem - a alma humana, os fenômenos sociais e suas diversas conseqüências históricas. Para Aristóteles (2001), a alma humana é composta pelas paixões, as faculdades e as disposições.

As paixões humanas são os sentimentos de prazer ou sofrimento, como apetites, cólera, medo, alegria, ganância. As faculdades estão relacionadas com as coisas das quais os homens sentem paixão: 
faculdade de amedontrar, de se alegrar. E, as disposições estão relacionadas à posição boa (virtude) ou má (vícios destrutivos) em relação às paixões.

Portanto, o homem precisaria desenvolver as disposições boas para suas paixões, para que então, a sociedade prossiga coexistindo. Segundo Hirschman (2002), durante o século XVII, um sentimento surgido no Renascimento tornoutse uma firme conviç̧ão: a filosofia moral e a religião não podiam mais reprimir as paixões destrutivas dos homens. A difícil tarefa então, foi entregue ao Estado. Porém, o Estado como o controlador das paixões humanas, como solução repressiva, não sobreviveu a uma análise mais detalhada das paixões no século XVII.

Hirschman (2002), alega também que entre os séculos XVI e XVIII, diversas correntes filosóficas articularam a idéia de aproveitar as paixões, em vez de reprimí-las. Desenvolveutse a idéia de que algumas paixões pudessem conter outras, consideradas mais destrutivas para a sociedade. A idéia foi distinguir as paixões consideradas boas, das consideradas destrutivas, a serem combatidas. Desenvolveu-se então, uma brilhante solução, buscar o interesse próprio (paixões boas), pois assim, poder-se-ia manter a ordem social, ter uma sociedade política mais previsível, estável. A estabilidade e previsibilidade social seriam finalmente alcançadas.

Shon (1971), argumenta que o homem busca com ansiedade a certeza, a estabilidade, que nem sempre são duradouras ou mesmo verdadeiras. Para Hirschman (2002), os desagrados relacionados à idéia do homem buscando o interesse próprio, foram paulatinamente dissipados, pois o mundo se tornaria um lugar mais previsível.

Quando o homem busca atender seus próprios interesses torna-se mais previsível, transparente e estável. O termo 'interesse', até o final do século XVI se relacionava com a totalidade das aspirações humanas, não se limitando aos aspectos materiais. Por sua vez, Maquiavel ao prescrever as ações e a defesa dos interesses do príncipe, influenciou diversas correntes filosóficas/econômicas. Estas correntes separaram as paixões boas, das destrutivas, e elegeram a busca do interesse próprio, como a paixão boa que combateria as destrutivas.

A escolha do interesse próprio, buscando o ganho material, o enriquecimento, passa a ser, não somente moral e socialmente aceitáveis, mas indispensáveis para controlar as paixões dos homens. O desenvolvimento do comércio e o aumento da riqueza material (paixões boas, os interesses próprios) passam a ser ideologicamente corretos e permitem a estabilidade social. Esta ideologia amparada por várias correntes filosóficas, adota o paradigma econômico ou de mercado, como fundamental na ordenação da vida humana associada.

As empresas que proliferaram nos séculos XIX e XX foram guiadas pela busca do interesse próprio, nasceram sob o denominado, paradigma do mercado. Ou seja, as empresas se firmaram como o meio mais eficiente e eficaz para a obtenção de uma sociedade estável.

O entendimento de que é o interesse próprio que contribui para o desenvolvimento do homem e para a manutenção de uma sociedade estável, sustenta a denominada economia de mercado. Para Cruz Júnior (1988), não surgiram alternativas que confrontassem a premissa de que o mercado é o instrumento ideal para a alocação de recursos. Ao que parece, a economia de mercado deveria ser a solução para controlar as paixões humanas e ainda, fazer com que estas trabalhem pelo social, buscando a melhoria da condição humana.

No entanto, o mercado, inicialmente concebido como grande fonte de melhoria da condição humana, provou não ser o que se idealizou. Seu grande objetivo passou a se concentrar demasiadamente no 
lucro. A condição humana e social passou a ser colocada em segundo plano. O Estado passa então, a ser a grande fonte provedora do bem estar social.

Porém, o Estado do bemrestar social com seus serviços de baixa qualidade, aliados a falta de recursos financeiros, teve dificuldades em atender as demandas sociais. Este fato gerou uma crise de confiança na capacidade do Estado, exigindo a busca de novas alternativas.

As empresas passaram a exercer um papel diferenciado do tradicional - provedoras de bens e serviços. Ou seja, a sociedade passou a reconhecer que as empresas como grandes portadoras e geradoras de riquezas materiais, também deveriam e poderiam assumir uma maior responsabilidade para com a sociedade, assumindo e participando de causas sociais.

Assim, a falência do Estado como mantenedor de necessidades básicas do cidadão, juntamente com a escassez do trabalho ou emprego, especialmente no final do século XX, abriram espaço e necessidade para o fenômeno da responsabilidade social corporativa. A empresa então, deixou de ser apenas a produtora de bens e serviços, para participar e influenciar diretamente outras dimensões sociais.

\section{A INFLUÊNCIA DA RESPONSABILIDADE SOCIAL CORPORATIVA}

Assumindo sua responsabilidade social, as empresas desenvolvem diversos programas, dentre eles: relações com os empregados, serviço ao público e à comunidade, proteção ambiental, defesa do consumidor, assistência médica e educacional, desenvolvimento e renovação urbana, cultura, arte e recreação (MEGGINSON; MOSLEY; PIETRI JR.,1998). Vassallo (2000), argumenta que as ações de responsabilidade social estabelecem de maneira obsessiva uma transformação no modo das empresas conduzirem seus negócios. No Brasil, essa transformação se deve ao fato dos problemas estruturais como fome, violência, doenças, carência de educação formal.

As empresas, como grandes centros de poder e que detém grandes volumes de recursos financeiros e humanos, têm papel fundamental para enfrentar tais problemas estruturais. A responsabilidade social tornou-se abrangente, envolvendo uma dimensão de responsabilidade para com toda a cadeia produtiva da empresa: clientes, funcionários, fornecedores, além da comunidade, ambiente e sociedade como um todo.

No entanto, considera-se que a atuação empresarial pode ser abrangente e preocupante. Pode ser preocupante por dois motivos diferentes. A primeira preocupação deve-se ao fato de não contar com algumas empresas cumprindo com seu papel social e, então, dificultando ainda mais um desenvolvimento social sustentável e mais humano.

As empresas são grandes centros de poder econômico e político, interferindo diretamente na dinâmica social. Assim, assumindo causas sociais as empresas estariam devolvendo à sociedade parte dos recursos humanos, naturais, financeiros que consumiram para a alavancagem do lucro de sua atividade. Esta situação tem levado diversos atores sociais a legitimarem a responsabilidade social corporativa.

A segunda preocupação, porém, lança um desafio maior, pois envolve uma reflexão sobre qual sociedade é mais apropriada não somente ao desenvolvimento econômico, mas ao desenvolvimento humano. Esta discussão pode se tormar incômoda, pois, existe uma crença, que parece estar no inconsciente coletivo, de que o desenvolvimento econômico é o próprio desenvolvimento da capacidade humana e garantidor do bem-comum, transformando-se no denominado paradigma 
econômico. $\mathrm{O}$ avanço do poder das empresas na sociedade abarca além de suas responsabilidades tradicionais, como fornecedora de bens e serviços, outra responsabilidade bem mais ampla, a do bemestar social do homem, afirmando-se como propagadora e garantidora do bem-comum.

Acredita-se que tanto o Estado como a sociedade, não poderiam se privar da discussão sobre a possibilidade objetiva das empresas terem a permissão social para serem as únicas ou as mais importantes reguladoras da vida humana podendo arbitrar o que deve ou não ser feito pela e para a sociedade. Ou seja, a empresa além de prover a sociedade de bens e serviços, terá sob seus domínios o bem-estar do cidadão. Tal situação pode remeter à fábula de Orwell (1998), que descreve o Grande Irmão, cujo poder era ilimitado sobre tudo e todos.

Barbosa (2001), considera que as empresas estão cada vez mais se tornando comunidades autosuficientes e se apóia em duas teses: as empresas são as mais importantes instituições do mundo contemporâneo e estão se transformando em instituições totais. Assim, as empresas estão transformando a vida humana, em seu aspecto mais íntimo.

Essa transformação passa por uma relação totalizante entre empresa e funcionários, bem como impacta também na sociedade como um todo. A empresa toma para si questões antes designadas a outros sistemas organizacionais, que se tornam periféricos. O que determina esse movimento é a lógica de mercado, a única que justifica o que deve ou não ser feito.

Para Enriquez (1997, p.10), “[...] o ponto essencial a ser assinalado é que a empresa difunde uma visão do futuro social [...]. Ela se encarrega não somente do desenvolvimento econômico da nação, mas também do seu desenvolvimento social, psicológico e cívico. Nenhum dos domínios da vida lhe é, a priori, proibido, pois ela se considera com 'responsabilidade ilimitada'".

Portanto, defende-se a idéia de que as ações de responsabilidade social corporativa sejam também delimitadas. A delimitação, ou pelo menos, a necessidade em instigar uma preocupação maior com a prática da responsabilidade social corporativa, nada tem a ver com os benefícios sociais gerados, mas com o avanço e, enfim, com o poderio por completo do mercado, do paradigma econômico, na vida humana associada.

Para Barbosa (2001), as empresas estão provocando na sociedade uma revolução silenciosa, o avanço totalitário, que precisa ser questionado. No entanto, não se pode conceber uma sociedade sem a produção de bens e serviços. O que se pretende, na verdade, é uma reavaliação da influência e das ações das empresas na sociedade. A preocupação aqui enfatizada de delimitar a responsabilidade social corporativa encontra eco na proposição da Teoria da Delimitação dos Sistemas Sociais, de Alberto Guerreiro Ramos, que considera a necessidade de um paradigma que alterne o econômico - o paradigma paraeconômico.

\section{A TEORIA DA DELIMITAÇÃO DOS SISTEMAS SOCIAIS}

A Teoria da Delimitação dos Sistemas Sociais (TDSS), proposta por Ramos (1989), tem o objetivo de reconceitualizar os sistemas sociais, nos quais predomina o paradigma de mercado. O paradigma de mercado é unidimensional, pois nele o mercado, as organizações econômicas são a orientação e a referência principal do ordenamento da vida em sociedade. 
A TDSS propõe um modelo social multidimensional, sendo composto por dois marcos ou pontos centrais. No primeiro ponto, o mercado é considerado um enclave legítimo e necessário, mas limitado e regulado, este novo modelo reflete o denominado paradigma paraeconômico. No paradigma paraeconômico existe espaço para outras organizações, não somente para as empresas, pois, o homem existe além de critérios econômicos, do exercício da razão instrumental. O homem é também um ser com razão substantiva.

$\mathrm{Na}$ articulação da TDSS, é explicitada a preocupação com o homem e a situação do uso da racionalidade humana especialmente voltada para atender o mercado. A razão permite que o homem ordene sua vida. De acordo com Ramos (1983), a razão humana tem duas dimensões: a razão substantiva e a instrumental.

É por meio da razão substantiva que o homem exerce suas escolhas, desenvolvendo seus próprios valores, crenças e virtudes. Sempre que suas escolhas são cerceadas ou limitadas há uma tentativa de despersonalização, de tornar o homem um ser meramente comportamental, unidimensional.

O uso da razão instrumental busca atingir os objetivos de maneira calculista, independente das ações ou atitudes que se fizerem necessárias. Ramos (1983), argumenta que a racionalidade humana em uma sociedade centrada no mercado acaba relegada a uma das dimensões, a racionalidade instrumental, enquanto a racionalidade substantiva tende a ser desprezada.

A TDSS tem o objetivo de resgatar a racionalidade plena, ou seja, resgatar a utilização potencial tanto da racionalidade instrumental como da substantiva. Para Cruz Júnior (1988), o conceito de delimitação dos sistemas sociais implica na visão de um macrocosmo multifacetado, no qual o mercado é apenas uma das facetas, onde os homens têm a oportunidade de exercer também sua racionalidade substantiva.

O segundo ponto da TDSS está relacionado à necessidade de um sistema de governo atuante, capaz de formular e implementar políticas distributivas para que as diversas organizações possam coexistir em equilíbrio, sem que uma em especial amplie em demasia seu poder. Quando o Estado não oferece condições mínimas ao cidadão, abre espaço para que outras organizações sociais o façam.

No entanto, a iniciativa e a propriedade privada são também condições fundamentais para a delimitação dos sistemas sociais. Na verdade, o Estado por meio de políticas governamentais possibilitaria a compatibilidade dos diversos enclaves sociais, evitando a superposição de um tipo de organização em especial. Assim, a TDSS é uma tentativa ou uma proposta de superar a internalização do mercado como fonte única norteadora da vida social.

Em princípio, a delimitação do enclave social econômico, ou seja, da atuação das empresas, pode se concretizar por meio de uma gestão organizacional voltada para ações de responsabilidade social. Porém, acredita-se ser necessária a disposição para refletir sobre a necessidade de também delimitar as ações sociais implementadas pelas empresas.

As ações de responsabilidade social corporativa podem levar a sociedade a legitimar as empresas como ordenadoras e provedoras centrais do bem-comum. As empresas têm assim seu poder ampliado, tornando-se necessário delimitá-lo, pois as empresas são apenas mais uma faceta social, com objetivos próprios e específicos.

Como ordenadoras da vida social, as empresas podem eclipsar o desenvolvimento pleno das potencialidades humanas, substituindo-o pelos objetivos empresariais. Torna-se, portanto, oportuno 
refletir sobre a estrutura dos sistemas sociais, buscando aquela que mais possa contribuir para a melhoria da qualidade de vida do homem multidimensional.

\section{CONSIDERAÇÕES FINAIS}

O paradigma de mercado é unidimensional, pois considera as empresas como importantes atores da sociedade, transformando-as nas principais ordenadoras da vida humana associada. Sustentadas por este paradigma, onde tudo é possível para que o lucro seja atingido, as empresas muitas vezes poluem, matam animais, destroem florestas e, principalmente, prejudicam a potencialidade total do homem.

O que a sociedade tem proposto e exigido, é delimitar as ações das empresas. A chamada responsabilidade social corporativa tem, a primeira vista, esta intenção. A delimitação social das empresas, por meio da cobrança de ações de responsabilidade social tem o grande mérito por alertar a sociedade das práticas empresariais nem sempre justas.

Porém, emerge a preocupação de que a empresa utilize as ações de cunho social para ampliar seu poder, tanto na dimensão interna, quanto na dimensão externa da empresa. Assim, a empresa pode tornar-se definitivamente o principal ator social. Como provedora do bem-comum, a empresa poderá tornar-se uma ou a própria 'Grande Senhora' da sociedade, ditando as normas de conduta e ética.

Ao invés da responsabilidade social corporativa delimitar o poder das empresas, pode acabar ampliandoo, quando se torna mais um meio da empresa justificar determinadas situações ou imposições tanto aos seus empregados, como à sociedade em geral. Além disso, a comunidade em geral pode tornar-se bastante tolerante aos abusos cometidos por uma empresa que financia hospitais, eventos culturais, ecológicos e sociais de modo geral.

Portanto, trata-se de uma excelente oportunidade para as empresas assumirem causas sociais. Ratifica-se, no entanto, que o envolvimento das empresas em causas sociais, também traz consequiências positivas e não pode ser desconsiderado, porém, inegavelmente pode ampliar o poder deste tipo de organização na sociedade.

Assim, considera-se que a proposta delineada por Ramos (1989), de delimitar os sistemas sociais é fortemente válida. O Estado e a sociedade organizada (ONG's, associações de classe, universidades, dentre outras), tem papel fundamental na reflexão sobre o avanço do poder de um tipo especial de organização na sociedade.

Considera-se ainda que a proposta do paradigma paraeconômico tem o mesmo propósito inicial do paradigma de mercado, ou seja, controlar as paixões humanas, contrapondo-as, equilibrando-as buscando um mundo mais constante e previsível. A grande diferenciação reside no fato de que o controle das paixões humanas pode acontecer, com a sustentação de várias organizações sociais, ao invés de uma única reguladora: o Estado, igreja ou empresa.

Além disso, o paradigma paraeconômico tem a pretensão de recuperar a plena potencialidade humana, através do exercício tanto da racionalidade instrumental, como da substantiva. O exercício pleno da racionalidade humana seria possibilitado através da coexistência equilibrada de organizações sociais, com diferentes objetivos, e não, somente ou principalmente, com o objetivo da acumulação de riquezas materiais. 
Acredita-se que o fenômeno responsabilidade social corporativa possa ser alvo de reflexões, visando beneficiar o homem, não somente um único tipo de organização, no caso, as empresas. Enquanto o Estado e a sociedade se propuserem somente a legitimar e a tratar o mercado, as empresas, como principais fontes reguladoras da vida humana, priorizando o acúmulo de riquezas em detrimento do bem estar do homem, continuarão existindo barreiras para a melhoria da condição humana.

\section{Artigo recebido em 10.09.2002. Aprovado em 17.12.2003.}

\section{REFERÊNCIAS BIBLIOGRÁFICAS}

ARISTÓTELES. Ética a Nicômaco. Coleção a obra-prima de cada autor. São Paulo: Ed. Martin Claret, 2001.

BARBOSA, L. O centro do universo. Exame. São Paulo, ano 35, n. 7, p.107-110, 4 abr. 2001.

CRUZ JUNIOR, J. B. da. Organização e administração de entidades públicas: aspectos políticos, econômicos e sociais de um paradigma emergente. Revista de Administração Pública. Rio de Janeiro, 22(3), p. 3-21, jul.-set., 1988.

ENRIQUEZ, E. Os desafios éticos nas organizações modernas. Revista de Administração de Empresas. São Paulo, v. 37, n. 2, abr./jun., 1997, p. 6-17.

FLYVBJERG, B. Esboço de uma ética aplicada ao desenvolvimento sustentável: Aristóteles, Foucault e a phrónesis progressiva. Revista Síntese. Belo Horizonte, v. 21, n. 66, p. 337-352, jul.-set., 1994.

HIRSCHMAN, A. O . As paixões e os interesses: argumentos políticos para o capitalismo antes de seu triunfo. Rio de Janeiro: Record, 2002.

MEGGINSON, L. MOSLEY, D. C.; PIETRI JR. P.H. Administração: conceitos e aplicações. 4.ed. São Paulo: Harbra, 1998.

ORWELL, G. 1984. 23 ed. São Paulo: Nacional, 1998.

RAMOS, A. G. A nova ciência das organizações: uma reconceituação da riqueza das nações. 2.ed.Rio de Janeiro: FGV, 1989.

Administração e contexto brasileiro: esboço de uma teoria geral da administração. Rio de Janeiro: FGV, 1983.

SCHON, D. Beyond the stable state. New York: The Norton Library, 1971.

VASSALLO, C. Um novo modelo de negócios. Exame. Guia de boa cidadania corporativa. São Paulo, edição 728, 2000, p. 8-11. Edição especial.

WOOD JR., T. Organizações espetaculares. Rio de Janeiro: Editora FGV, 2001. 


\section{Jocimari Tres Schroeder}

Professora da Universidade do Vale do Itajaí - UNIVALI. Mestre em Administração pela Universidade Federal de Santa Catarina - UFSC.

E-mail: jocimari@matrix.com.br

Endereço: Rua Dr. Arlécio de Souza Flor, 70 - apto 1202 - Ed. Reino Unido - Centro Itajaí SC, 88301-140.

Interesses de Pesquisa: estratégia e organizações, sustentabilidade e governança corporativa.

\section{Ivanir Schroeder}

Professor da Universidade do Vale do Itajaí - UNIVALI. Doutorando no Programa de Pós-Graduação em Engenharia de Produção da Escola Politécnica da USP. Mestre em Administração pela Universidade Federal de Santa Catarina - UFSC.

E-mail: ivanir@matrix.com.br

Endereço: Rua Dr. Arlécio de Souza Flor, 70 - apto 1202 - Ed. Reino Unido - Centro Itajaí SC, 88301-140.

Interesses de Pesquisa: estratégia e organizações, economia da produção, gestão econômica. 